\title{
Solvent effect in the polyethylene recovery from multilayer postconsumer aseptic packaging
}

\author{
Alejandro Cervantes-Reyes ${ }^{a}$, Alejandra Núñez-Pineda ${ }^{\mathrm{b}}$, Carlos Barrera-Díaz ${ }^{\mathrm{a}}$, Víctor Varela-Guerrero ${ }^{\mathrm{a}}$, \\ Gonzalo Martínez-Barrera ${ }^{c}$, Erick Cuevas-Yañez ${ }^{\mathrm{a}, *}$ \\ ${ }^{a}$ Centro Conjunto de Investigación en Química Sustentable UAEM-UNAM, Carretera Toluca-Atlacomulco Km 14.5, Toluca, Estado de México, Universidad Autónoma del Estado \\ de México 50200, Mexico

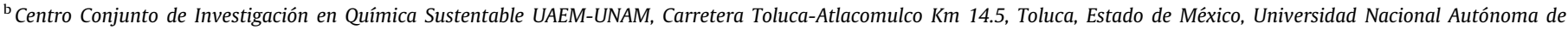 \\ México 50200, Mexico \\ ${ }^{\mathrm{c}}$ Laboratorio de Investigación y Desarrollo de Materiales Avanzados (LIDMA), Facultad de Química, Universidad Autónoma del Estado de México, Km 12 Carretera \\ Toluca-Atlacomulco, Campus San Cayetano, C.P. 50200 México, Mexico
}

\section{A R T I C L E I N F O}

Article history:

Received 29 October 2014

Accepted 25 January 2015

Available online 11 February 2015

\section{Keywords:}

Multilayer postconsumer aseptic packaging Polyethylene

PE-Al composite

Solvent

Separation

\begin{abstract}
A B S T R A C T
Polyethylene films were separated and recovered from polyethylene-aluminum composites derived from recycling multilayer postconsumer aseptic packaging. A brief study about the separation process by dissolving $\mathrm{PE}$-aluminum ( $\mathrm{PE}-\mathrm{Al}$ ) composites into a series of organic solvents with a combination of time and temperature is presented. Through this procedure, 56\% polyethylene is recovered from this kind of composites in optimized conditions. DSC and TGA studies were performed to determine the thermal stability of recovered polyethylene films and to establish a comparison with a PE reference commercial product, demonstrating that recovered polyethylene films kept their thermal properties.
\end{abstract}

(c) 2015 Elsevier Ltd. All rights reserved.

\section{Introduction}

Flexible multilayer packaging has been successfully used for the preservation of food and other products. However, once it has been used represents a serious environmental problem as an important part of solid wastes.

Multilayer packaging has a multicomposite structure made with paper, aluminum and polyethylene films which are gathered by temperature or by copolymerization with some additives as acrylic acid or vinyl acetate, where the cellulose part represents $75 \%$ of the total weight of the packaging, while aluminum films are estimated in $5 \%$. These films are coated and joined by polyethylene layers to avoid the contact of food with aluminum and to protect from external agents (Barrera-Díaz et al., 2014).

Although cellulose is recovered and reused in paper industry, the remaining solid wastes, namely, a mixture of low density polyethylene and aluminum composites, are still a demanding challenge today. An outstanding characteristic of polyethylene-aluminum

\footnotetext{
* Corresponding author. Tel.: +52 722276 6610x7734; fax: +52 7222175109. E-mail address: ecuevasy@uaemex.mx (E. Cuevas-Yañez).
}

(PE-Al) composites derived from postconsumer aseptic packaging is that both plastic and metal components are strongly adhered and they are hard to separate by mechanical processes. Therefore, the treatment and disposal protocols for this kind of wastes are limited. Currently, PE-Al composites are used as an alternative energy source by pyrolysis (Korkmaz et al., 2009) or they are reprocessed to plastics for secondary uses (Lopes and Felisberti, 2006; Hidalgo, 2011), or they are incinerated (Varžinskas et al., 2012). In all these cases, the total waste disposal problem is not completely resolved because residual aluminum and carbon dioxide are formed, or the selling prices of reprocessed materials are lower than those if aluminum and polyethylene were separately commercialized.

Inspired by these facts, we initiated an investigation in order to design a non-destructive procedure for the recovery of polyethylene from PE-Al composites. In this regard, we considered that certain solvents can solubilize polyethylene (Igwe, 2007), besides other plastics such as polystyrene are recycled by dissolution with appropriate solvents (García et al., 2009). Taking these precedent reports, we proposed in Fig. 1a recovery process for polyethylene from PE-Al composites using a plastic dissolution as recovery strategy. Herein is described a summary of our recent successful endeavors in this area. 


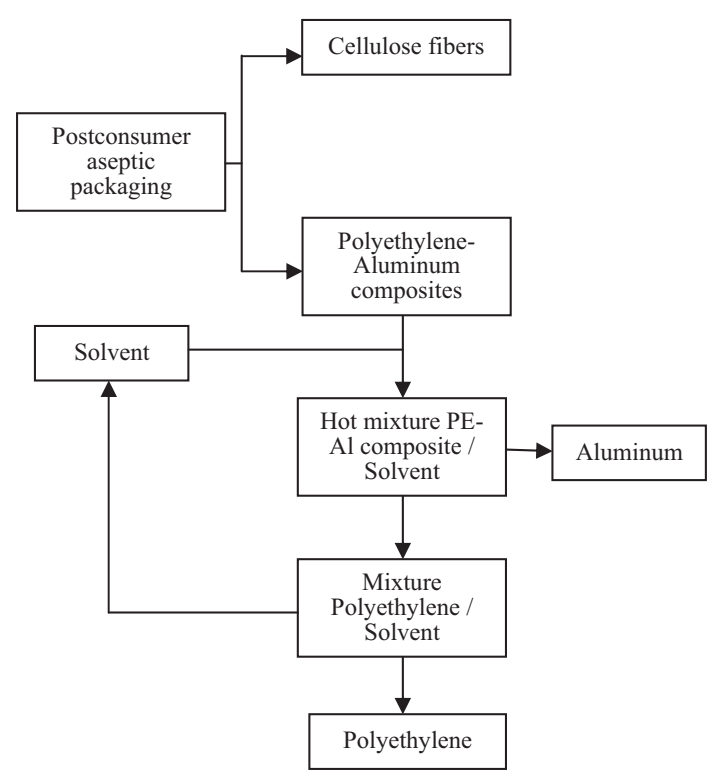

Fig. 1. General recovery process of polyethylene from PE-Al composites.

\section{Experimental}

\subsection{Materials}

Samples of polyethylene-aluminum (PE-Al) composites were provided from a Mexican company devoted to the paper recovery from Tetra Pak ${ }^{\circledR}$ postconsumer aseptic packaging and they were used as received in approximately $1.5 \mathrm{~g}$ portions and divided using an extrusion machine. The samples were dried under vacuum by a $24 \mathrm{~h}$ period. Commercial polyethylene reference was provided by 3 M United States Company. Industrial grade solvents were used without further purification.

\subsection{Separation general procedure}

A mixture of PE-Al composites ( $1.5 \mathrm{~g}$ ) and the corresponding solvent $(200 \mathrm{~mL})$ were stirred at reflux temperature for $6 \mathrm{~h}$. The mixture was cooled to room temperature and the organic solvent with PE films samples was separated by decantation. The aluminum residue was washed with hot solvent and filtered. The organic fractions were joined and the solvent was removed under vacuum, and the resulting PE films were dried under vacuum for $24 \mathrm{~h}$. After drying, $0.1 \mathrm{~mm}$ films were obtained. The yield percentage of recovered PE was obtained by difference of starting and final quantities of introduced samples, and by direct weighing of separated PE films.

\subsection{Analysis methods}

The FTIR spectra were recorded on a Bruker Tensor 27 spectrophotometer instrument with Platinum ATR accessory. TGA/DSC studies were carried out in a thermal analyzer Netzsch STA 449 F3 Jupiter with a heating ramp of $10^{\circ} \mathrm{C} / \mathrm{min}$, in a nitrogen atmosphere at a flow rate of $20 \mathrm{~mL} / \mathrm{min}$. Samples were heated from room temperature to $560{ }^{\circ} \mathrm{C}$; aluminum crucibles of 5-mm diameter were used. Savitzky-Golay smoothing algorithm was employed for TGA curves.

\section{Results and discussion}

\subsection{Separation of PE-Al composites using organic solvents}

In the initial studies, organic non-polar solvents were used at room temperature, and we found that after $48 \mathrm{~h}$, PE films were separated in low yields. Therefore, the contact treatment time was increased (Table 1). Although superior yields were obtained, they still remain low. However, an important increasing in the PE yield was observed using higher temperatures in shorter times. These experiments showed that the temperature plays an important role in the separation process.

In the next step, several solvents were tested and the results are summarized in Table 2. Diverse effects were noted by the treatment of PE-Al composites with the studied solvents at reflux temperature. First, we confirmed that the best yields were obtained when solvents with high boiling points are used. According to Igwe (2007), xylene showed the best ability for dissolving PE and afforded the best yields. Moreover, the recovery yield is also dependent of the solvent polarity. For example, PE separation in hexane resulted more efficient than using THF even though these solvents have similar boiling points, a similar situation occurred with ethyl acetate (b.p. $77^{\circ} \mathrm{C}$ ) and ethanol (b.p. $78^{\circ} \mathrm{C}$ ). These facts suggest that non-polar solvents with higher boiling points are the best for this kind of processes.

\subsection{Analysis of PE films}

Recovered PE films were analyzed by some techniques. For instance, the FT-IR spectrum (Fig. 2) of PE films recovered with xylene showed intense bands at $2916 \mathrm{~cm}^{-1}\left(\mathrm{CH}_{2} \mathrm{v}_{\mathrm{as}}\right)$, and $2848 \mathrm{~cm}^{-1}\left(\mathrm{CH}_{2} \mathrm{~V}_{\mathrm{s}}\right) \mathrm{cm}^{-1}$ due to the stretching vibration of alkane $\mathrm{C}-\mathrm{H}$ bonds which were assigned to methylene groups present in the polyethylene linear structure. Moreover, distinctive $\mathrm{CH}_{2}$ bands at around $1463 \mathrm{~cm}^{-1}\left(\mathrm{CH}_{2}\right.$ scissor) and $720 \mathrm{~cm}^{-1}\left(\left[\mathrm{CH}_{2}\right]_{n}\right.$ rock) were observed. However, analogous bands are observed for paraffin waxes derived from polyethylene degradation (Korkmaz et al., 2009). For this reason, this analysis technique is not conclusive to determine composition or purity of PE films.

On the other hand, recovered PE films were analyzed through DSC and TGA studies focused to determine the thermal stability and polyethylene content of recovered products and to establish a comparison with a PE reference commercial product.

Table 1

Separation of polymer films from PE-Al composites using non-polar solvents after one extraction. The experiments were repeated three times.

\begin{tabular}{lllcl}
\hline Entry & Temperature $\left({ }^{\circ} \mathrm{C}\right)$ & Solvent & Time $(\mathrm{h})$ & \% Recovered polymer \\
\hline 1 & R.T. & Xylene & 48 & 14 \\
2 & R.T. & Xylene & 168 & 42 \\
3 & 70 & Xylene & 24 & 30 \\
4 & R.T. & Toluene & 48 & 18 \\
5 & R.T. & Toluene & 168 & 22 \\
6 & 55 & Toluene & 24 & 27 \\
7 & R.T. & Hexane & 48 & 16 \\
8 & R.T. & Hexane & 168 & 25 \\
\hline
\end{tabular}

Table 2

Separation of polymer films from PE-Al composites using non-polar solvents at reflux temperature and after one extraction. The experiments were repeated three times.

\begin{tabular}{lllll}
\hline Entry & Solvent & Boling point $\left({ }^{\circ} \mathrm{C}\right)$ & Time $(\mathrm{h})$ & \% Recovered polymer \\
\hline 1 & Ether & 35 & 6 & 24 \\
2 & $\mathrm{CH}_{2} \mathrm{Cl}_{2}$ & 39 & 6 & 3 \\
3 & Acetone & 56 & 6 & 7 \\
4 & THF & 67 & 6 & 7.5 \\
5 & Hexane & 68 & 6 & 33 \\
6 & AcOEt & 77 & 6 & 16 \\
7 & Ethanol & 78 & & 2 \\
8 & Toluene & 110 & 6 & 37 \\
9 & Xylene & 141 & 16 & 56 \\
\hline
\end{tabular}




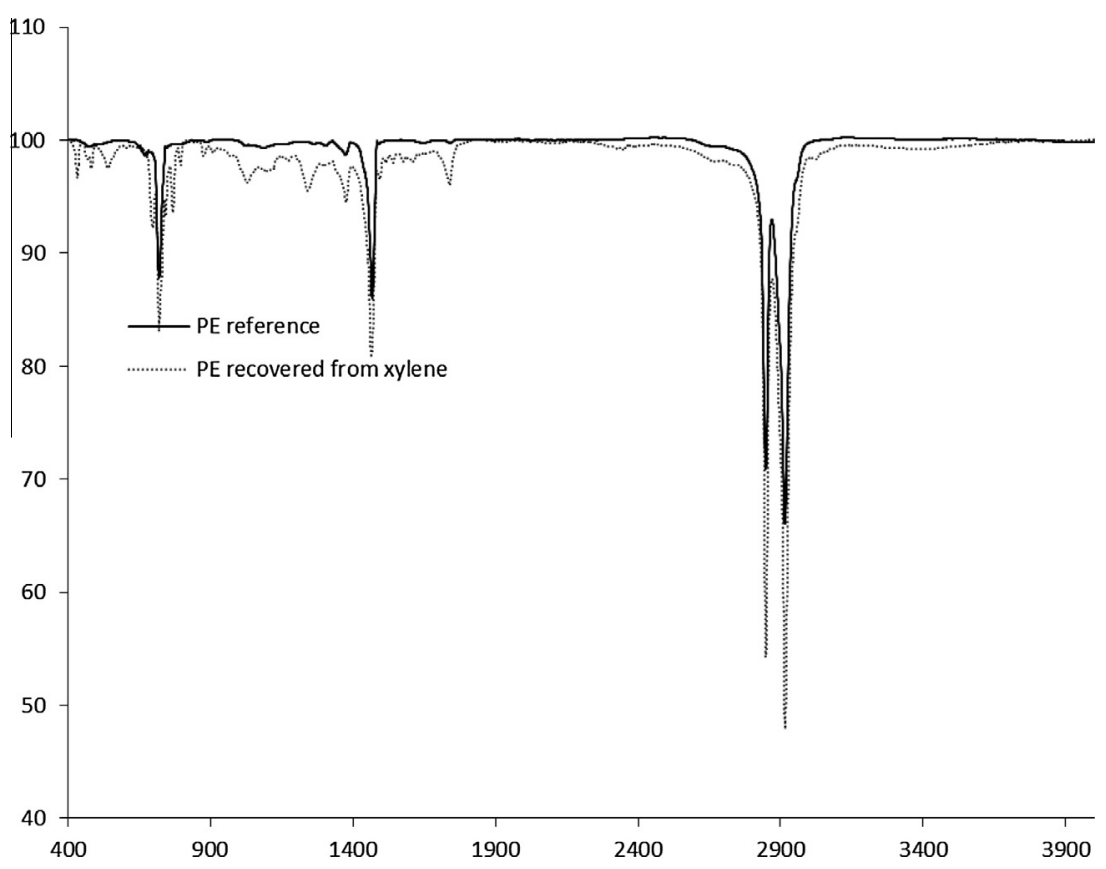

Fig. 2. FT-IR spectrum of the PE film recovered with xylene and PE reference.

In preliminary works, paraffin wax and polyethylene have been studied by TGA. Whereas the weight of paraffin decreased in a temperature range between $157^{\circ} \mathrm{C}$ and $300{ }^{\circ} \mathrm{C}$ (Craig et al., 1971), the most important weight loss for polyethylene takes place at above $400{ }^{\circ} \mathrm{C}$ (Contat-Rodrigo et al., 2002). In our case, the PE content was analyzed by TGA and some noteworthy features were identified. In Fig. 3, the mass loss of both recovered and reference PE films is shown. A first weight loss is detected around 100$250{ }^{\circ} \mathrm{C}$, which is associated to the loss of volatile solvents and humidity. The second and most important weight loss is located at $350-550{ }^{\circ} \mathrm{C}$, consistent with the degradation of the polymeric chains. Furthermore, the composition of the products was determined by TGA curves analysis. From these results, the PE content in films recovered from hexane reflux, toluene reflux and xylene reflux was $71 \%, 66 \%$ and $83 \%$, respectively. In this way, xylene showed the best capacity for extracting PE and provided the best results. Thus, TGA studies demonstrate that after recovery, PE films are able to maintain their original structure without significant decay properties.

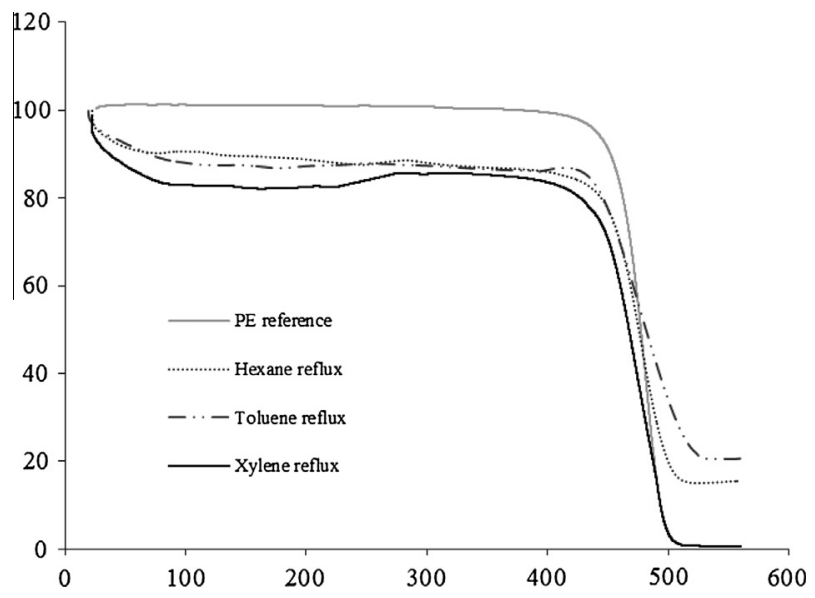

Fig. 3. TG thermograms of recovered PE films using diverse solvents
DSC studies were determined on recovered PE films and the corresponding DSC curves of investigated samples and a PE reference are plotted in Fig. 4. Two main endothermic processes were observed, a characteristic melting peak at $100-111^{\circ} \mathrm{C}$ corresponding to the fusion of PE with chains containing little or no branches. The second peak at $440-500{ }^{\circ} \mathrm{C}$ showed the decomposition of PE. These profiles are similar to other reported in the literature (Camargo et al., 2008; Prasad, 1998), in opposite to that described for paraffin waxes with melting peaks between 45 and $60{ }^{\circ} \mathrm{C}$ (Ukrainczyk et al., 2010). In addition, Table 3 shows the energy parameters involved in the fusion and decomposition processes of $\mathrm{PE}$. In the case of PE recovered films from xylene reflux, the

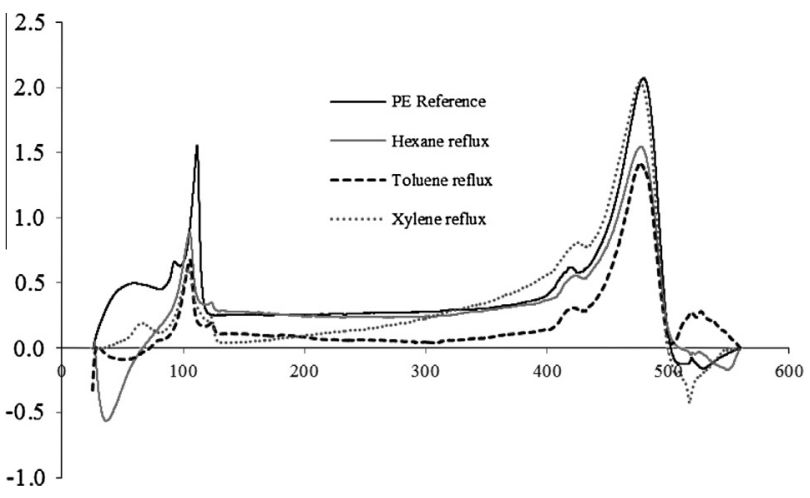

Fig. 4. DSC curves for recovered PE films using diverse solvents.

Table 3

DSC analysis of PE recovered and PE reference.

\begin{tabular}{llll}
\hline Sample & $\begin{array}{l}\text { Fusion temperature } \\
\text { of } \mathrm{PE}\left({ }^{\circ} \mathrm{C}\right)\end{array}$ & $\begin{array}{l}\text { Fusion energy } \\
\text { of } \mathrm{PE}(\mathrm{J} / \mathrm{g})\end{array}$ & $\begin{array}{l}\text { Decomposition } \\
\text { energy of } \mathrm{PE}(\mathrm{J} / \mathrm{g})\end{array}$ \\
\hline PET reference & 111.4 & 81.9 & 542.0 \\
Hexane reflux & 105.3 & 45.9 & 348.6 \\
Toluene reflux & 105.3 & 44.6 & 301.3 \\
Xylene reflux & 104.2 & 57.9 & 514.5 \\
\hline
\end{tabular}


enthalpy of fusion and enthalpy of decomposition are the nearest to PE reference data. This indicates that structural properties of $P E$ recovered with xylene were affected in lower grade. These results support the TGA studies and confirm the presence of polymer after recovery treatment.

\section{Conclusions}

In the present study, a separation process using industrial solvents was developed to separate and recover polyethylene from multilayer postconsumer aseptic packaging. Non-polar solvents showed more efficiency in the recovery process of PE films from $\mathrm{PE}-\mathrm{Al}$ composites using a polymer dissolving as key step in the recovery strategy. This efficiency can reach $56 \%$ under xylene reflux conditions. The recovered PE films presented good thermal properties which indicate high purity. The recovery process proposed displays an alternative solution to the multilayer solid waste problem. The showed experiments represent a departure point for future studies with the objective to increase the yield of the recovery process and to study the remnant $\mathrm{PE}-\mathrm{Al}$ mixtures. These characteristics suggest that this proposal will enjoy widespread application.

\section{Acknowledgments}

Financial support from SIEA-UAEMEX (Project No. 3410/ $2013 \mathrm{M}$ ) and CONACYT (Project No. 135053) is gratefully acknowledged. The authors would like to N. Zavala and L.Triana for the technical support.

\section{References}

Barrera-Díaz, C., Varela-Guerrero, V., Cuevas-Yañez, E., Martínez-Barrera, G., RoaMorales, G., García Morales, M.A., 2014. Use of recycled aluminumpolyethylene composite films as anodic electrodes for electrocoagulation of wastewater. Int. J. Electrochem. Sci. 9, 1034-1043.

Camargo, M., Camargo-Forte, M.M., Wolf, C.R., 2008. Linear low density polyethylene thermal fractionation by DSC technique. Int. J. Polym. Anal Charact. 13, 49-65.

Contat-Rodrigo, L., Ribes-Greus, A., Imrie, C.T., 2002. Thermal analysis of highdensity polyethylene and low-density polyethylene with enhanced biodegradability. J. Appl. Polym. Sci. 86, 764-772.

Craig, R.G., Powers, J.M., Peyton, F.A., 1971. Thermogravimetric analysis of waxes. J. Dent. Res. 50, 450-454.

García, M.T., Duque, G., Gracia, I., de Lucas, A., Rodríguez, J.F., 2009. Recycling extruded polystyrene by dissolution with suitable solvents. J. Mater. Cycles Waste $11,2-5$.

Hidalgo, M., 2011. Manufacturing rigid board by packaging waste containing aluminum and polyethylene. J. Sci. Ind. Res. India 70, 232-234.

Igwe, I.O., 2007. Uptake of aromatic solvents by polyethylene films. J. Appl. Polym. Sci. 104, 3849-3854.

Korkmaz, A., Yanik, J., MihaiBrebu, M., Vasile, C., 2009. Pyrolysis of the tetra pak Waste Manage. 29, 2836-2841.

Lopes, C.M.A., Felisberti, M.A., 2006. Composite of low-density polyethylene and aluminum obtained from the recycling of postconsumer aseptic packaging. J. Appl. Polym. Sci. 101, 3183-3191.

Prasad, A., 1998. A quantitative analysis of low density polyethylene and linear low density polyethylene blends by differential scanning calorimetry and Fourier transform infrared spectroscopy methods. Polym. Eng. Sci. 38, 1716-1728.

Ukrainczyk, N., Kurajica, S., Sipusic, J., 2010. Thermophysical comparison of five commercial paraffin waxes as latent heat storage materials. Chem. Biochem. Eng. Q. 24, 129-137.

Varžinskas, V., Staniškis, J.K., Knašyte, M., 2012. Decision-making support system based on LCA for aseptic packaging recycling. Waste Manage. Res. 30, 931-939. 